\title{
Percepções de um filosofar
}

Ricardo Parra Catarina

Graduando em Ciências Sociais

Faculdade de Ciências e Letras de Araraquara (UNESP)

Resumo: A partir de minha experiência como monitor de um projeto de extensão universitária da Faculdade de Filosofia e Ciências e Letras de Araraquara com aulas de filosofia em um abrigo residencial, buscarei delinear algumas percepções acerca desta prática - o filosofar.

Tudo começa como um sonho ruim, daqueles que você acorda se debatendo contra o travesseiro, respiração ofegante, frio na espinha. Este é o retrato que faço a respeito da descoberta do saber, através da filosofia. Compreender que podemos saber muito mais, pela simples reflexão, simples observação, é mágico, porém desesperador. Intrinsecamente desesperador, já que crenças fincadas em nossa mente podem ser destruídas, dogmas postos ao indivíduo podem ser quebrados, deixando-o perdido, com medo e assombrado com o mundo que se desvela. Procurar respostas para tudo. Encontrar abismos. Assim é a filosofia: a abertura de portas para o inacreditável mundo real, para a compreensão do visível e invisível, do objetivo e subjetivo. Um mundo mais fantástico que qualquer conto de fadas e mais real que a consciência que você tem de si próprio.

Bem, antes de começar a relatar minha experiência no projeto, gostaria de fazer um autolevantamento do porque a filosofia. Essa poderia ser uma história bonita, com final feliz. Mas prefiro que apenas seja o mais realista possível. E o real é doloroso. A ignorância é uma benção, o saber, um caminho sem volta. Não conheço pessoa alguma que tendo encontrado esse caminho, tenha desistido e percorrido o outro. O meu papel talvez seja mostrar que existem meios para que o saber seja mais prazeroso, apesar de se tornar uma chaga aberta dentro da cabeça do indivíduo. É a filosofia algo dialético desde esse seu princípio.

Conheci o método Lipman de maneira um tanto quanto prosaica. Queria fazer uma oficina de filosofia, com crianças. Mas achei sem nexo ensinar a elas a história da filosofia. Pois afinal, apesar de pessoalmente achá-la importante, acreditei que não era essa a filosofia que eu gostaria de utilizar na oficina. Foi quando procurando livros na biblioteca sobre o assunto, encontrei um, que contava a experiência de Lipman. Achei fantástico. Encontrei também uma professora que trabalhava com o tema. Mas isso tempos depois. A professora Paula me acolheu então em seu grupo, único aluno de ciências sociais dentro de um local em que a pedagogia dominava. Mas talvez esse fato tenha sido um diferencial interessante. Via na filosofia um modo de saber, de raciocinar, importante na formação de qualquer ser. E ainda aposto todas as minhas fichas na educação como algo emancipador, como algo que pode trazer aos indivíduos não uma melhor condição de vida, mas sim a cidadania, termo excessivamente discutido, porém visto apenas 
de um viés, o viés acadêmico. Colocar idéias na cabeça de um aluno não é o bastante, se este não conseguir produzi-las.

Mas pensar que o método de Lipman é a panacéia maravilhosa que todos esperam, é insensato, pois é claro que todo programa tem suas falhas. Aliás, suas novelas filosóficas até poderiam ser utilizadas no projeto, mas com sérias restrições, por apresentarem um grau de irrealidade de condições e situações que beirariam o absurdo, o fantástico.

Comentarei a seguir um pouco da experiência do ano passado com a prática de filosofia. O local onde fizemos as aplicações de filosofia possui uma problemática que o próprio Lipman talvez não conheça de perto. As aplicações feitas por mim e mais duas monitoras e colaboradoras (as quais devo muito) se destinavam a crianças com idades entre sete e doze anos de idade, que moram, ou moravam (às vezes é apenas um lugar transitório), no abrigo residencial "Casa da Criança Cristo Rei". Ou seja, elas moravam lá devido a medidas judiciais que as fizeram deixar os seus lares e seus pais. As aplicações de filosofia foram, então, realizadas com crianças com atraso escolar e que não possuíam uma estrutura familiar. Não estávamos em um espaço/modelo escolar. Ao contrário, elas possuíam um modelo de casa, estando intimamente ligados, em tudo, tanto nas brincadeiras, quanto nas discussões. Agravando, parece-me que a escola que freqüentam deixa a desejar quanto ao ensino, visto que tentativas de escrita passam longe do ideal. Tínhamos ainda no recinto poucos realmente interessados, e muitos encontravam-se lá por mera obrigação, o que deixava a prática algo insuportável, para elas e para nós. Assim, tínhamos todas as dificuldades que alguém poderia ter para a prática da filosofia.

Mais então do que em qualquer outra situação, teríamos que desenvolver táticas para prender-lhes a atenção, poder conseguir discussões agradáveis, que mostrassem um mundo diferente. Diria que o maior medo que eu tinha, não era o de subverter aquelas mentes infantis, mas sim o de falhar com meu principal objetivo. Falarei um pouco sobre essas táticas, que julgo serem de extrema importância, já que a respeito de aplicações, métodos, temos materiais já publicados.

Em uma das aplicações, eu observava um quadro interessante: das quinze crianças ao meu redor, duas prestavam a atenção, na história, na discussão. Perguntei a elas o porquê do desinteresse. Diziam que não queriam escutar histórias, que elas eram chatas... Muito barulho... Percebi que falar mais alto não adiantaria. As duas garotas que prestavam atenção já estavam desanimadas com a atitude dos colegas. Foi quando um estalo na minha mente me fez fazer algo interessante. Chamei as duas garotas para sentarem perto de mim e comecei a sussurrar a história para elas. As outras monitoras, Lia e Carol, logo notaram a minha intenção e começaram a instigar os outros. Quando percebi, todos estavam em completo silêncio, me ouvindo sussurrar a história. Formei a "comunidade do silêncio", à qual só pertencia àqueles que pudessem falar extremamente baixo, um de cada vez, escutando os companheiros. Mas eles ainda achavam aquela coisa de contar histórias uma coisa chata. Foi quando eu sugeri fazermos uma história em 
conjunto. O resultado foi maravilhoso, mas assustador: por mais que eu e as outras monitoras quiséssemos criar uma história alegre e divertida, eles conseguiam fazer com que elas fossem violentas, sombrias, nas quais colocavam em xeque o conceito de vida, morte, saúde e amizade, da maneira mais natural possível. Nossa discussão se pautou na história que eles mesmos contaram.

Outra vez, nada fazia com que eles ficassem em silêncio. Me aproveitei da presença de um aparelho de som, com $\mathrm{CD}$, e coloquei para eles ouvirem um disco que estava perdido dentro da minha bolsa. Era um CD de blues bem antigo de John Lee Hooker, na qual ele cantava acompanhado apenas de um violão. Eu sabia que aquilo soaria de forma estranha a aqueles ouvidos infantis, acostumados com porcarias fm. Coloquei o som bem baixo. Perguntei quem ouvia. É claro que pediram para aumentar o volume. Eu disse: "Ok!" e fiz o contrário, baixei ainda mais. Perguntei se todos ouviam. Disseram: "para a gente ouvir, você tem que aumentar, e não baixar o volume!" Baixei mais um pouco o volume, só um fiozinho de volume. Quando ia perguntar, o silêncio reinava e pediram para eu não falar nada, se não eles não ouviriam o som! Isso é que é dialética! Contei para eles a história do blues, passando pelo rock, vindo para o samba no Brasil, discutindo os ritmos. Eles dançaram, e foi algo totalmente diferente do que tínhamos planejado.

Planejar...bom, mas nem sempre adiantou. Quantas vezes tínhamos uma coisa em mente e, ao nos depararmos com as crianças, mudávamos totalmente o rumo pensado. É preciso ter cartas nas mangas. Para discutir arte, deixamos elas fazerem seus próprios desenhos, e depois comentarem, compreenderem, que arte não é só coisas bonitas, mas sim sentimentos. Falamos sobre a natureza, sobre a imaginação com poemas de Manoel de Barros. Além do que, nosso público nos fez entender que suas necessidades eram outras. Para outras necessidades, outras histórias. Então o GEPFC (Grupo de Estudos e Pesquisas Filosofia para Crianças) foi de extrema importância. A criação de histórias sob certa demanda foi incrível. Desenvolvi um lado que até então não conhecia, meus lados criativos, imaginativos. E talvez por isso, todo esse texto tenha um caráter mais literário que científico; mais desabafo que critico. Talvez por isso, as cores fortes sejam.

Pensar como foi aquele ano, ano de 2003, me deixa melancólico. Lembro-me de como sabia que toda vez que saísse da minha casa, voltaria depressivo e acreditando que tudo aquilo era besteira, que elas não precisavam de filosofia, $e$ sim de afagos, afeto, amizades. Sabia que além dessa tentativa de mostrar um novo mundo - essa utopia pedagógica de crer que a educação é a salvação, a solução para todos os males - que a maiêutica socrática daria a luz a um Alien. E doía meu coração com uma chaga. Pensava: aquela geração seria perdida, engolida pelo capital, explorada pelo trabalho alienado e, por mais que tentássemos, eles jamais seriam cidadãos, jamais poderiam vislumbrar um bom futuro; possivelmente apenas reproduziriam todo o mal que herdamos da nossa sociedade excludente, falida.

Precisei encarar um papel de "emancipador de pensamentos" para ver que o nosso mundo é um tanto pior do que podemos imaginar. Que o papel assistencialista do 
governo é pouco até para dar assistência. Que a universidade pública se fecha em suas torres de marfim enquanto topa com funcionários que mal sabem escrever o próprio nome.

De quem é a culpa por aquelas crianças não conseguirem maiores abstrações do que acreditar no que não vêem e de reproduzirem entre elas mesmas toda forma de preconceito e discriminação, não percebendo que o diferente também merece respeito? Hoje, alguém cuida delas. Mas, e amanhã? Tenho então a função, mais social que pedagógica, de tentar tirar essas almas dum purgatório real que é a sociedade. Busco também a minha redenção. Lipman estava certo: a filosofia cria condições para um melhor desenvolvimento do intelecto. Mas a nossa missão deve ser mais nobre. Devemos não só criar estes tipos de condições, como também mostrar a luz que iluminará um futuro que não precisa ser apenas de mera reprodução da ordem já instituída. Devemos nos deter na destruição de todas as falsas impressões de mundo, reconstruindo crianças que, mais do que tudo, sejam o "futuro da nação". Que nação é essa que queremos?

Não devemos desvalorizar a cultura que elas possuem, mas sim fazer com que pensem no porquê devem valorizar esta cultura. Mais do que tudo os "porquês"... A semente da discórdia deve ser lançada a cada nova questão - acho que isto importa mais do que, por exemplo, o desenvolvimento do raciocínio lógico. Foi o que tentei, tentamos fazer, eu, a Lia, a Carol. E a cada nova aplicação, um novo dissabor, uma nova flecha no coração por não termos feito com que aquelas crianças enxergassem, com os olhos desvendados, toda a claridade da parte externa da caverna. Se uma delas sair da caverna, estaremos felizes.

\section{REFERÊNCIA BIBLIOGRÁFICA}

OLIVEIRA, Paula Ramos. Filosofia para a formação da criança. São Paulo: Thomson Learning, 2004. 